\title{
Modelagem econométrica dos preços de carros populares do tipo hatch utilizando a regressão linear múltipla
}

\author{
Rodrigo de Vasconcellos Viana Medeiros ${ }^{1}$ \\ Naiara Costa Vidiga?
}

\begin{abstract}
Resumo: O presente estudo tem o objetivo de elaborar um modelo que explique as oscilações nos preços de venda dos automóveis populares usados e seminovos do tipo hatch. Foram coletadas 385 observações contendo o preço de venda e as principais características das principais marcas de veículos negociados no mercado interno brasileiro. Para construir o modelo a técnica utilizada foi a regressão linear múltipla. Os resultados obtidos evidenciaram que $85,5 \%$ da variabilidade dos preços de vendas podem ser explicadas pelas variáveis quilometragem $(\mathrm{km})$, idade (id), potência $(\mathrm{mt})$ do motor (1.000 cilindradas ou maior), combustível único ou flex (tc), existência de ar-condicionado (ar), veículo com 2 ou 4 portas (por), existência de dispositivo de alarme (al), modelos dos automóveis (Gol, mod1; Palio, mod2; Novo Uno, mod3, Corsa, mod5; Celta, mod6), cor branca (c2), existência de airbag (ab) e presença de dispositivo elétrico nos vidros (vid). Em relação aos aspectos de validade e ajuste, o desempenho do modelo foi satisfatório, tendo em vista o fato de não violar os pressupostos necessários para a execução da regressão linear múltipla. O modelo final provou ser uma ferramenta que contribui para a redução de assimetria informacional nesse mercado, pois revelou os principais atributos responsáveis pela oscilação dos preços dos automóveis.
\end{abstract}

Palavras-chave: Carros usados e seminovos. Regressão linear múltipla. Modelos.

Abstract: This study aims to elaborate a model that explains the oscillations in the selling prices of used popular cars. We collected 385 obsevartions containing the sale price and main characteristics of main vehicle brands traded in the brazilian domestic market. To construct the model, multiple linear regression was used as a tecnique. The result showed that $85.5 \%$ of the sales price variability can be explained by variables mileage ( $\mathrm{km})$, age (id), power (mt) of the engine (1,000 cc or greater), single or flex fuel (tc), air conditioner (air), 2 or 4 door vehicles (c2), existence of airbag (ab) and presence of a device (al), car models (Gol, mod1, Palio, mod2, Novo Uno, mod3, Corsa, mod5, Celta, mod6) electric in the glasses (vid). Regarding the validity and adjustment aspects, the performance of the model was satisfactory considering the low percentage errors in the estimates made and also because it did not violate assumptions necessary for the execution of multiple linear regression. The final model proved to be a tool that contributes to the reduction of informational asymmetry in this market, as it revelead that main atributes that make the prices of automobiles oscillates.

Keywords: Used cars. Multiple linear regression. Models.

\footnotetext{
${ }^{1}$ Graduado em Ciências Econômicas pela Universidade Católica de Petrópolis (UCP). Mestre em Economia Doméstica pela Universidade Federal de Viçosa (UFV). Professor Substituto no Instituto Federal do Sudeste de Minas Gerais - Campus Rio Pomba. E-mail: rodrigodevasconcellos.medeiros@gmail.com.

2 Graduanda em Administração pelo Instituto Federal do Sudeste de Minas Gerais (IF SUDESTE-MG). E-mail: naiaracosta998@gmail.com.
}

Página 47 Caderno de Ciências Sociais Aplicadas, Vitória da Conquista/BA, vol. 15, nº 26, ano 15, p. 47-68, jul/dez 2018. 


\section{Introdução}

A importância da indústria automobilística pode ser evidenciada pelos números que esta apresenta na economia global. Cerca de oito milhões de pessoas em todo o mundo trabalham diretamente em montadoras de veículos, $50 \%$ do consumo mundial de borracha e 15\% do consumo de vidro são destinados ao setor automotivo, que movimenta cerca de US\$ 3 trilhões por ano (CASOTTI e GOLDENSTEIN, 2008a).

No Brasil, de acordo com Casotti e Goldenstein (2008b), a indústria automobilística passou recentemente por algumas fases que vão desde a estagnação (1990-1992), ascensão (1993-1997), queda (1998-2003) até a sua retomada (2004-2008). No ano de 2017, os dados da Associação Nacional dos Fabricantes de Veículos Automotores (ANFAVEA, 2017) registram o melhor do mês da história em exportações para o setor, com cerca de 73 mil unidades exportadas, número $28,8 \%$ superior ao registrado em novembro de 2016.

Esses dados comprovam que, sem dúvida, o mercado automobilístico brasileiro representa um dos principais medidores do desempenho econômico do país. Além disso, se a demanda externa por carros novos cresceu substancialmente, internamente outro segmento se destacou no ano 2017. A demanda por carros populares seminovos e usados $^{3}$ dentro da economia brasileira obteve um ritmo de crescimento 7,2\% maior se comparado ao ano de 2016, representando 10,7 milhões de unidades negociadas (FENABRAVE, 2018). Apesar desse aumento, a Fenabrave (Federação Nacional da Distribuição de Veículos) afirma que o setor ainda está em recuperação.

Estudar o comportamento dos preços de carros usados e seminovos é de grande relevância, pois para cada negociação de um carro novo ocorrem cinco negociações de usados e/ou seminovos. Em outras palavras, a relação de vendas entre novos e usados é de um para cinco, o que mostra a grande participação desse setor no mercado interno automobilístico brasileiro (ANFAVEA, 2017; SANTOS, 2015).

As variações encontradas nos preços de carros usados e seminovos dependem de suas características intrínsecas (cor, ano de fabricação, motor, entre outras) e também das informações que o consumidor dispõe sobre aquele veículo. Belo e Brasil (2006) exemplificam essa questão ao citar a situação de um vendedor que possui pleno conhecimento do funcionamento e da qualidade do carro

\footnotetext{
3 Segundo a ANFAVEA, um veículo é considerado seminovo quando seu tempo de emplacamento não ultrapassa dois anos. A partir de dois anos de emplacamento o veículo é considerado usado.
}

Página 48 Caderno de Ciências Sociais Aplicadas, Vitória da Conquista/BA, vol. 15, n 26, ano 15, p. 47-68, jul/dez 2018. 
que está sendo vendido, ao passo que quem está disposto a comprar desconhece tais informações, gerando, dessa maneira, uma assimetria de informações naquela negociação e, consequentemente, no mercado.

A ocorrência de informação assimétrica podem gerar falhas no mercado, contribuindo para o surgimento de conflitos de interesses entre os agentes e diminuição do bem-estar de todos os envolvidos, tornando o mercado ineficiente. Além disso, insuficiência de informações provoca distorções na precificação dos bens negociados naquele mercado e dificulta possíveis ajustes de preços (BELO e BRASIL, 2006; GODOY, SILVA e NETO, 2004).

Diante disso, o presente estudo pretende contribuir para a redução da assimetria informacional no mercado de carros usados e seminovos, ao propor um modelo de regressão linear múltipla que seja capaz de explicar as variações de preço desses bens. Especificamente, o objetivo é encontrar quais são as variáveis que mais contribuem para o aumento e redução de tais preços.

Apesar da existência de alguns mecanismos que servem de parâmetro para a verificação dos preços de carros novos, usados e seminovos como tabela FIPE, Oliveira (2015) declara que a diferença entre os preços sugeridos pela referida tabela e os preços praticados no mercado estão aumentando, podendo chegar a quase $\mathrm{R} \$ 6.000,00$ em alguns veículos. Isso mostra que ainda é necessário optar por modelos que alcancem melhores ajustes para os preços desse mercado.

\section{O Problema da informação assimétrica nos mercados}

A assimetria de informação atinge um mercado quando a qualidade do produto ofertado se torna duvidosa. Desse modo, os consumidores se sentem incertos sobre sua escolha e, caso queiram tomar a decisão mais acertada, seria necessário buscar mais informações relacionadas ao bem em questão. Porém, existem vários mercados em que a busca por informações pode se tornar muito custosa ou até mesmo impossível e isso pode causar sérios problemas ao funcionamento eficiente do mercado (VARIAN, 2006).

A falta de informações provoca o fenômeno da seleção adversa, uma forma de falha de mercado que ocorre justamente quando existem informações assimétricas de um produto com diferentes qualidades vendido pelo mesmo preço. Devido a essa falha, o mercado se torna ineficiente, ou seja, muitos produtos de baixa qualidade serão vendidos e apenas uma pequena parcela dos de alta qualidade será vendida. Isso ocorre porque quando um vendedor tenta comercializar um bem de baixa

Página 49 Caderno de Ciências Sociais Aplicadas, Vitória da Conquista/BA, vol. 15, nº 26, ano 15, p. 47-68, jul/dez 2018. 
qualidade no mercado a percepção dos consumidores é afetada e, nesse sentido, estes estarão menos propensos a pagar um preço mais alto por um produto de maior qualidade devido à incerteza causada pela falta de conhecimento acerca do produto. É essa externalidade que cria o problema da seleção adversa e, consequentemente, a falha de mercado (PINDYCK e RUBINFELD, 2006; VARIAN, 2006).

Akerlof (1970), em seu artigo seminal, foi o primeiro a constatar que a assimetria de informação causava redução de bem-estar entre compradores e vendedores, chegando a recomendar que, em alguns casos, a intervenção do governo poderia aumentar o bem-estar de todas as partes e, assim, evitar a concentração de poder no mercado. Para exemplificar os efeitos da assimetria de informação, o autor cita o mercado de carros usados. Supondo que o comprador não consegue diferenciar carros de boa qualidade dos de má qualidade, ele opta por pagar um preço médio, situado abaixo do preço de carros bons e acima do dos ruins. Em outras palavras, isso causaria um aumento da oferta dos carros de má qualidade e uma redução na oferta dos de boa qualidade, chegando ao ponto de, no limite, os carros de má qualidade expulsarem os carros de boa qualidade do mercado em analogia ao que acontecia com a Lei de Gresham

A lógica usada por Akerlof (1970) pode ser estendida para entender as implicações da assimetria de informação em vários outros mercados. Para o setor de saúde pode ser citado o estudo desenvolvido por Godoy, Silva e Neto (2004), que analisaram os efeitos da assimetria informacional e da regulação do governo nos preços dos contratos de planos de saúde. Segundo os autores, a legislação regulatória do setor impôs diferenciação de preços de acordo com a idade do consumidor, dificultando a discriminação de preços conforme o grau de risco de cada indivíduo e provocando uma seleção adversa nesse mercado.

De todas as áreas econômicas, as finanças representam a que a assimetria de informação é mais estudada. Para exemplificar, pode-se citar o trabalho desenvolvido de Albanez e Valle (2009), que analisaram os impactos da assimetria de informação na estrutura de capital de empresas brasileiras abertas. Para medir o nível de assimetria informacional, os autores buscaram proxies como o nível de governança corporativa das empresas, listagem de empresas que foram indicadas ao troféu transparência de informações e empresas brasileiras que negociaram suas ações nas bolsas americanas. Com base em um modelo de regressão linear múltipla para dados em painel, os autores chegaram ao

\footnotetext{
${ }^{4}$ A Lei de Gresham é um princípio econômico que afirma que a má moeda tende a eliminar do mercado a boa moeda, ou seja, se uma moeda tem seu valor determinado acima do mercado por uma autoridade monetária e uma outra moeda também tem seu valor fixado pela mesma autoridade, porém, abaixo do mercado, esta última tende a ser expulsa pela primeira. Para maiores detalhes sobre o tema, recomenda-se Marcondes (1998).
}

Página 50 Caderno de Ciências Sociais Aplicadas, Vitória da Conquista/BA, vol. 15, nº 26, ano 15, p. 47-68, jul/dez 2018. 
seguinte resultado: as empresas com menor grau de assimetria informacional são aquelas com maior endividamento. Isso ocorre pelo fato de essas empresas proporcionarem mais facilidades para seus credores avaliarem o risco, aumentando a oferta de crédito para estas e reduzindo custos provenientes de seleção adversa.

Estudos em outras áreas do conhecimento evidenciam de que maneira a presença de informações assimétricas pode afetar o funcionamento de mercados. São exemplos os trabalhos de: Zonatto e Larvada (2017), os quais destacam a relação negativa entre as informações assimétricas e o estresse no ambiente de trabalho; França (2005), que desenvolveu um modelo para avaliar como a eficiência na gestão de organizações sociais pode ser impactado pela presença da assimetria informacional; e Tavares, Moreira e Pereira (2013), que desenvolveram um estudo destacando as distorções nos preços do mercado imobiliário de Portugal devido à assimetria de informação existente entre os mediadores comerciais e os compradores.

\section{Estudos sobre o mercado de carros no Brasil}

O mercado de carros usados/seminovos é seguramente mais aquecido que o de carros novos. No EUA, por exemplo, 75\% dos veículos transacionados por ano correspondem a carros usados (GAVAZZA, LIZZERI e ROKETSKIY, 2014). No Brasil, a situação não é diferente. Para 2017, aproximadamente $80 \%$ dos automóveis transacionados naquele ano foram no mercado de carros usados e seminovos (FENABRAVE, 2017).

Apesar da existência de estudos que contribuíram de maneira expressiva para a temática, a literatura brasileira não é muito extensa no que tange as análises de variações de preços ou demanda por automóveis. Um dos primeiros estudos a investigar a demanda por automóveis no Brasil foi realizado por Baumgarten Jr. (1972). Embora o foco de seu estudo seja estimar as funções de demanda no curto e longo prazos para a compra de novos veículos, os resultados obtidos pelos modelos evidenciaram a grande influência das variações de preços no mercado de carros usados e seminovos na demanda dos automóveis novos, afetando diretamente a decisão do consumidor de comprar ou não um carro novo.

Silveira et al. (2006) enfatizam a importância de se investigar os determinantes de consumo por automóveis. Em seu estudo, destacaram a importância das variáveis renda per capita, preço de combustíveis (gasolina e álcool) e vida média dos veículos na decisão dos consumidores. Um dos principais resultados é que a venda de carros bicombustíveis no mercado brasileiro tem sido fortemente

Página 51 Caderno de Ciências Sociais Aplicadas, Vitória da Conquista/BA, vol. 15, n 26, ano 15, p. 47-68, jul/dez 2018. 
estimulada pela diferença nos preços dos combustíveis. Especificamente, quando a relação entre preço e gasolina aumenta 1\%, o consumo de veículos movidos a álcool cresce aproximadamente 1,57\%.

De acordo com De Negri (1998), a escolha do consumidor sobre qual carro adquirir envolve muitas variáveis que podem ser classificadas como agregadas e desagregadas. As primeiras estão relacionadas principalmente à média de preço dos carros (novos) e da renda das famílias; as segundas estão atreladas aos custos de manutenção do veículo, idade do carro (usados e seminovos) e aos preços desses bens. No caso do Brasil, especificamente, o autor declara que a demanda está fortemente ligada à elasticidade preço de demanda por veículos novos (que se mostrou elástica), evidenciando que esse bem pode ser substituído por outros automóveis como os importados ou mesmo os usados.

Os resultados encontrados pela regressão em série de tempo no trabalho de De Negri (1998) vão ao encontro do estudo realizado por Fauth, Moraes e Clezar (2009). Em seu trabalho, os autores encontram fortes indícios quanto ao efeito substituição entre carros novos e usados, inviabilizando a rejeição da hipótese proposta em seu estudo (não existência de substituição entre esses bens). Dessa forma, ao analisar a demanda por carros no mercado brasileiro, surgem lacunas de difícil preenchimento no que se refere ao modo como os preços do mercado de automóveis usados e seminovos oscilam em determinado período.

Diante disso, Fonseca (1997) buscou investigar de que maneira a qualidade dos carros transacionados no mercado brasileiro podia impactar os preços de venda desses bens. Além disso, o autor incluiu em seu modelo de regressão algumas variáveis explicativas desagregadas, visando aumentar seu poder de explicação para os vários períodos estudados. Entre os resultados observados, é importante citar que as variáveis de performance (velocidade máxima e consumo médio de combustível) e as físicas (quatro portas, tipo de combustível, carro de luxo ou popular) foram significativas para explicar as variações dos preços, principalmente no período entre 1992-1994.

Além disso, ressalta Fonseca (1997), um problema comum em identificar as características relevantes que impactam os preços dos automóveis é descobrir quais variáveis são, de fato, importantes para o consumidor. Logo, os compradores ao comparar os preços praticados no mercado enfrentam o dilema de escolher entre uma melhor performance ou qualidades físicas dos carros. Porém, devido à existência de assimetria informacional, é mais complexo para um consumidor avaliar variáveis de desempenho do que aquelas relacionadas aos aspectos físicos do veículo ${ }^{5}$. Sendo assim, em modelos de

${ }^{5}$ Uma vez que cada consumidor determina subjetivamente qual característica é melhor para ele.

Página 52 Caderno de Ciências Sociais Aplicadas, Vitória da Conquista/BA, vol. 15, n 26, ano 15, p. 47-68, jul/dez 2018. 
oscilações de preço para períodos curtos pode-se assumir como proxy de desempenho algumas variáveis atreladas as qualidades físicas do carro sem que isso afete significativamente as estimações do modelo.

$\mathrm{Na}$ opinião de Resende e Scarpel (2009), os modelos que visam mensurar a precificação de veículos devem-se pautar principalmente no conjunto de atributos que o automóvel possui. Em seu estudo, os autores utilizaram um modelo de preços hedônicos para avaliar a importância das características físicas de veículos nacionais. Além disso, o estudo buscou estabelecer a relevância de tais características de forma que o preço de veículos ainda inexistentes possa ser provisionado. O modelo abarcou as seguintes variáveis explicativas: marca, potência do motor, nível de luxo, número de portas, tipo de combustível e comprimento do veículo. Após a análise, os resultados apontaram as principais características que impactam positivamente o preço do veículo: potência do motor, grau de luxo e marca. Além disso, o estudo revelou que o tipo de combustível usado nos veículos não é um atributo importante para a precificação dos automóveis nacionais.

De forma semelhante, Souza, Avila e Silva (2007) investigaram o modo como o acréscimo de alguns atributos nos veículos alterava a relação preço-satisfação dos veículos populares novos. Utilizando um modelo de regressão linear para preços hedônicos, os autores fizeram um levantamento de preços e características dos veículos populares das cinco montadoras do país (ano base 2005). Atributos como pintura metálica, aquecedor interno, ar-condicionado, direção hidráulica, limpador de vidros traseiros, trio elétrico, quatro portas, rádio com cd, rodas de liga leve, airbag, motor com 16 válvulas e carroceria sedan serviram de variáveis explicativas na análise do modelo. Segundo o resultado, os principais elementos na relação preço-satisfação eram, em ordem de importância, airbag, ar-condicionado, quatro portas, carroceria sedan e direção hidráulica.

Ainda de acordo com Souza, Avila e Silva (2007), as variáveis limpador traseiro, desembaçador, aquecedor e pintura metálica têm menor importância na composição dos preços e, consequentemente, pouco afetaram a relação preço-satisfação. Assim, conclui-se que o modelo exposto é de fato um padrão que pode ser empregado no mercado automobilístico, oferecendo características confiáveis para a determinação do preço e também de valores intrínsecos quanto a essas características.

Página 53 Caderno de Ciências Sociais Aplicadas, Vitória da Conquista/BA, vol. 15, nº 26, ano 15, p. 47-68, jul/dez 2018. 


\section{Aspectos metodológicos do modelo proposto}

\section{Método}

A pesquisa utilizou o método quantitativo e fundamenta-se na construção de um modelo que busque evidenciar a relação de causa e efeito entre variáveis previamente selecionadas. É importante lembrar que, para um modelo ser capaz de explicar realisticamente as relações entre as variáveis, uma série de pressupostos deve ser satisfeita (WOOLDRIGDE, 2010). Assim, com o objetivo de identificar as principais características que expliquem o preço dos carros usados e seminovos e encontrar um modelo que estime tais preços de maneira satisfatória, foi usada a técnica de regressão linear múltipla com a abordagem de preços hedônicos.

De acordo com Dantas, Magalhães e Vergolino (2007), esse tipo de modelo busca determinar qual é a importância marginal de cada característica do bem em estudo (automóveis) na formação do seu preço. Por definição, os preços hedônicos podem ser considerados os preços implícitos dos atributos do bem e são revelados para os consumidores por meio dos preços observados dos produtos diferenciados e, eventualmente, das quantidades específicas associadas a ele.

Tradicionalmente, um modelo de regressão linear múltipla é aquele que possui mais de uma variável explicativa (independente), relacionada a uma variável a ser explicada (dependente). Esse modelo pode ser representado pela equação 1:

$$
Y=\beta_{0}+\sum_{j=1}^{k} \beta_{j} X_{j}+\varepsilon
$$

Onde Y é a variável a ser explicada, $X_{j}, j=0,1, \ldots, k$ são as variáveis explicativas ou regressores, $\beta_{j}, j=0,1, \ldots, k$ são os coeficientes estimados e representam as variações esperadas em $\mathrm{Y}$ quando ocorrer uma variação em algum $X_{j}$, permanecendo todas as demais variáveis constantes e $\varepsilon$ representa um termo aleatório de erro (resíduo), onde está contida toda a variabilidade em Y que não pode ser explicadas pelas variáveis explicativas do modelo.

Os estimadores da regressão podem ser calculados de diversas maneiras. Uma das formas de se encontrar os coeficientes é pelo método dos mínimos quadrados. Segundo Wooldrigde (2010), nesse

Página 54 Caderno de Ciências Sociais Aplicadas, Vitória da Conquista/BA, vol. 15, n 26, ano 15, p. 47-68, jul/dez 2018. 
método os coeficientes "betas" são estimados de tal maneira que a soma dos quadrados dos resíduos será minimizada.

\section{Variáveis do estudo}

As variáveis incluídas no estudo foram selecionadas com base nos trabalhos pesquisados. Apesar de a literatura investigada não avaliar diretamente as oscilações de preços dos automóveis, esses estudos contribuíram para que o levantamento de variáveis fosse feito de forma que as proxies alcançassem a meta de explicar com maior fidedignidade as mudanças nos preços. Além disso, diante da escassa literatura no que diz respeito à análise dessas variáveis desagregadas, na coleta de dados priorizaram-se as variáveis com fontes públicas.

Entre as possíveis variáveis explicativas, optou-se por incluir no modelo os elementos quilometragem, idade do automóvel, modelo, portas, ar-condicionado, alarme, tipo de direção, airbag, tipo de combustível, motor, cor e vidros elétricos. A escolha dessas variáveis ocorre em razão do que a literatura, em partes, já havia consagrado como características determinantes nos preços (modelo, tipo de combustível e motor) e também pela disponibilidade da fonte de dados consultada. Para o levantamento da amostra, foi escolhido o Mercado Livre pelo fato de este site fornecer informações detalhadas dos veículos e também por ser uma companhia líder em anúncios de comércio eletrônico. Segundo a ferramenta de medição de tráfego on-line Alexa Rank, o site em questão classifica-se entre os 100 mais visitados do mundo e é o segundo portal de anúncios de carros mais antigo do Brasil.

Com relação às variáveis, a idade e a quilometragem dos veículos caracterizam-se como métricas. As demais variáveis podem ser classificadas de dummies, ou seja, variáveis auxiliares que buscam medir o impacto de características qualitativas existentes em cada observação. Geralmente, essas variáveis assumem os valores 0 ou 1 indicando, respectivamente, a ausência e a presença de determinada característica. Porém, quando uma variável possui várias características que são mutuamente excludentes, é necessário criar mais de uma variável dummy. Em linhas gerais, se existem $k$ características, deve-se elaborar $k-1$ variáveis dummies. O quadro 1 apresenta a síntese das variáveis utilizadas para a construção do modelo.

Página 55 Caderno de Ciências Sociais Aplicadas, Vitória da Conquista/BA, vol. 15, n 26, ano 15, p. 47-68, jul/dez 2018. 
Quadro 1 - Variáveis utilizadas para a construção do modelo.

\begin{tabular}{|c|l|}
\hline Variáveis & \multicolumn{1}{|c|}{ Definição } \\
\hline Preço (P) & Valor do veículo, em reais, pago pelos consumidores. \\
\hline Quilometragem (km) & Distância total percorrida, em quilômetros, pelo automóvel. \\
\hline Idade (id) & Tempo de fabricação, em anos, os automóveis. \\
\hline Modelo6 1 (mod.1) & Variável dummy que indica se o carro é do modelo Gol. \\
\hline Modelo 2 (mod. 2) & Variável dummy que indica se o carro é do modelo Palio. \\
\hline Modelo 3 (mod. 3) & Variável dummy que indica se o carro é do modelo Novo Uno. \\
\hline Modelo 4 (mod. 4) & Variável dummy que indica se o carro é do modelo Fiesta. \\
\hline Modelo 5 (mod. 5) & Variável dummy que indica se o carro é do modelo Corsa. \\
\hline Modelo 6 (mod. 6) & Variável dummy que indica se o carro é do modelo Celta. \\
\hline Portas (por) & Variável dummy que indica se o carro quando possui quatro portas ou não. \\
\hline Ar-condicionado (ar) & Variável dummy que indica se o automóvel possui ar condicionado ou não. \\
\hline Alarme (al) & Proxy para a segurança externa que indica se veículo tem dispositivo de alarme ou não. \\
\hline Tipo de direção (dir.) & $\begin{array}{l}\text { Proxy para a dirigibilidade proporcionada em que se mensura o efeito nos preços caso o } \\
\text { carro tenha direção elétrica ou hidráulica. }\end{array}$ \\
\hline Airbag (ab) & Proxy para a segurança interna que indica se o automóvel tem o dispositivo ou não. \\
\hline Tipo de combustível (tc) & Variável dummy que indica se o veículo é flex ou não. \\
\hline Motor (mt) & Variável dummy que indica se o carro tem mais de 1.000 cilindradas ou não. \\
\hline Cor 1 (c1) & Variável dummy que indica que o carro possui a cor preta. \\
\hline Cor 2 (c2) & Variável dummy que indica que o carro possui a cor branca. \\
\hline Cor (c3) & Variável dummy que indica que o carro possui a cor prata. \\
\hline Cor 4 (c4) & Variável dummy que indica que o carro possui a cor vermelha. \\
\hline Cor (c5) & Variável dummy que indica que o carro possui a cor cinza. \\
\hline Cor 6 (c6) & Variável dummy que indica que o carro possui a cor azul. \\
\hline Vidro (vid) & Variável dummy que indica se o automóvel possui vidros elétricos. \\
\hline
\end{tabular}
Fonte: Elaborado pelos autores (2018).

Assim, o modelo proposto inicialmente pode ser representado pela equação 3:

$$
\begin{aligned}
& P=\beta_{0}+\beta_{1} k m+\beta_{2} i d+\beta_{3} \bmod 1+\beta_{4} \bmod 2+\beta_{5} \bmod 3+\beta_{6} \bmod 4+ \\
& \beta_{7} \bmod 5+\beta_{8} \bmod 6+\beta_{9} \text { por }+\beta_{10} a r+\beta_{11} a l+\beta_{12} \operatorname{dir}+\beta_{13} a b+\beta_{14} t c+ \\
& \beta_{15} m t+\beta_{16} c 1+\beta_{17} c 2+\beta_{18} c 3+\beta_{19} c 4+\beta_{20} c 5+\beta_{21} c 6+\beta_{22} \text { vid }
\end{aligned}
$$

\section{Resultados para o modelo aplicado}

Para a composição da amostra dos automóveis do tipo hatch e o levantamento dos principais modelos vendidos, foi realizada a medição da participação de cada um nas vendas anuais em 2017. A tabela 1 apresenta o quantitativo para cada modelo pesquisado.

\footnotetext{
${ }^{6}$ Para a escolha dos modelos, foi realizado um levantamento dos 10 carros usados e seminovos mais vendidos no Brasil. Entre eles, os 7 primeiros modelos vendidos eram do tipo hatch e os demais do tipo sedan ou utilitário. Assim, para que as estimações representassem maior confiabilidade, foram analisados somente os modelos do tipo hatch.
}

Página 56 Caderno de Ciências Sociais Aplicadas, Vitória da Conquista/BA, vol. 15, nº 26, ano 15, p. 47-68, jul/dez 2018. 


\section{- Cadernos de CiêncIas SOCIAIS APLICADAS}

Tabela 1 - Participação de cada modelo nas vendas totais de usados.

\begin{tabular}{ccc}
\hline Modelo & Participação (\%) & Média de vendas (anual) \\
\hline Gol & 29,15 & 1.059 .300 \\
Palio & 18,05 & 678.300 \\
Novo Uno & 17,36 & 652.428 \\
Fiesta & 8,07 & 303.204 \\
Corsa & 8,48 & 318.504 \\
Celta & 10,56 & 396.948 \\
Fox & 8,33 & 313.008 \\
\hline
\end{tabular}

Fonte: Elaborado pelos autores com base nos dados da FENABARAVE (2017).

Com a finalidade de representar maior confiabilidade, foram coletadas 385 observações seguindo a participação nas vendas de cada modelo. Retirando-se os dados inconsistentes ${ }^{7}$, a amostra final foi composta por 366 veículos. A tabela 2 exibe algumas medidas descritivas dos automóveis pesquisados.

Tabela 2 - Medidas descritivas das variáveis quantitativas.

\begin{tabular}{ccccccc}
\hline Variáveis & $\mathbf{N}$ & Mínimo & Máximo & Média & Mediana & Desvio \\
\hline $\mathrm{P}$ & 366 & $5.454,00$ & $57.890,00$ & $24.418,73$ & $21.985,00$ & $9.716,18$ \\
$\mathrm{~km}$ & 366 & 79,00 & $260.000,00$ & $81.314,53$ & $78.800,00$ & $44.299,37$ \\
$\mathrm{id}$ & 366 & 1,00 & 18,00 & 6,91 & 13,00 & 4,10 \\
\hline
\end{tabular}

Fonte: Dados da pesquisa (2018).

Com base nos resultados encontrados na tabela 2, é possível afirmar que os carros usados e seminovos possuem, em média, preço $(\mathrm{P}) \mathrm{R} \$ 24.418,73$ com 81.314 quilômetros $(\mathrm{km})$ rodados e a média de idade (id), em anos, é aproximadamente igual a 7. Em relação à idade (id), o valor encontrado na amostra ficou aproximadamente 2,5 anos abaixo do que o anuário Fenabrave (2017) apontou em seu levantamento. Essa diferença pode ter sido causada pelo fato de o portal Mercado Livre anunciar automóveis de regiões eminentemente metropolitanas, chegando a praticamente inexistir veículos de cidades mais afastadas dos grandes centros. Além disso, observando os valores mínimos e máximos, verifica-se que tanto a variável preço como a quilometragem apresentaram uma elevada variabilidade, justificando dessa maneira os desvios padrão encontrados.

${ }^{7}$ Por exemplo, carros fabricados no ano 2000 e zero quilômetro.

Página 57 Caderno de Ciências Sociais Aplicadas, Vitória da Conquista/BA, vol. 15, nº 26, ano 15, p. 47-68, jul/dez 2018. 
Os resultados da tabela 2 podem ser alterados substancialmente se os modelos dos automóveis forem considerados fator de discriminação. Assim, é importante que se conheçam as medidas descritivas do preço (P), idade (id) e quilometragem $(\mathrm{km})$ de acordo com o modelo do carro. A tabela 3 apresenta os resultados de tais variáveis segundo o modelo.

Tabela 3 - Estatísticas descritivas de variáveis selecionadas segundo o modelo do carro.

\begin{tabular}{|c|c|c|c|c|}
\hline Modelo & $\mathbf{N}$ & Preço médio & $\begin{array}{l}\text { Quilometragem } \\
\text { média }\end{array}$ & Idade média \\
\hline Gol & 103 & $\begin{array}{l}23.196,38 \\
(8.954,38)\end{array}$ & $\begin{array}{c}82.282,32 \\
(46.195,83)\end{array}$ & $\begin{array}{c}7,14 \\
(4,59)\end{array}$ \\
\hline Palio & 67 & $\begin{array}{l}23.181,42 \\
(9.211,48)\end{array}$ & $\begin{array}{c}87.426,03 \\
(46.320,47)\end{array}$ & $\begin{array}{c}7,43 \\
(4,23)\end{array}$ \\
\hline Novo Uno & 45 & $\begin{array}{l}28.011,49 \\
(6.966,27)\end{array}$ & $\begin{array}{c}52.987,09 \\
(25.285,76)\end{array}$ & $\begin{array}{c}3,80 \\
(2,15)\end{array}$ \\
\hline Fiesta & 37 & $\begin{array}{c}33.250,57 \\
(11.828,98)\end{array}$ & $\begin{array}{c}75.003,27 \\
(33.758,95)\end{array}$ & $\begin{array}{c}5,18 \\
(2,81)\end{array}$ \\
\hline Corsa & 35 & $\begin{array}{l}18.614,29 \\
(4.158,37)\end{array}$ & $\begin{array}{c}93.831,46 \\
(60.313,45)\end{array}$ & $\begin{array}{l}10,05 \\
(3,25)\end{array}$ \\
\hline Celta & 43 & $\begin{array}{l}17.002,00 \\
(4.241,43)\end{array}$ & $\begin{array}{c}99.628,09 \\
(35.392,61)\end{array}$ & $\begin{array}{c}8,74 \\
(3,45)\end{array}$ \\
\hline Fox & 36 & $\begin{array}{l}31.152,72 \\
(9.653,33)\end{array}$ & $\begin{array}{l}75.023,50 \\
(37.811,67)\end{array}$ & $\begin{array}{c}5,69 \\
(3,13)\end{array}$ \\
\hline
\end{tabular}

Fonte: Dados da pesquisa (2018).

Obs: Os valores em parênteses representam os desvios padrão.

As estatísticas da tabela 3 revelaram que o carro com maior preço de revenda no mercado de usados e seminovos foi o modelo Fiesta. Por outro lado, o modelo Celta foi o automóvel de menor valor de revenda. Apesar de não possuir a maior média de idade, o Celta foi o carro que apresentou maior quilometragem rodada, atingindo quase 100.000 quilômetros na média. Esse resultado confirma o que a literatura (MATTOS e BARROS, 2006) aponta sobre a variável quilometragem, isto é, quanto mais o veículo circular maior será a depreciação deste no mercado para revenda.

Com relação à idade média dos modelos, os resultados da tabela 3 apontam: o Corsa possui a maior idade entre os pesquisados e o Novo Uno a menor idade média. A menor idade atribuída ao Novo Uno ocorre porque antes de 2010 essa versão não existia. Tal característica parece não ter afetado tanto os preços, pois carros com maior média de idade (Fox e Fiesta) obtiveram maiores médias em seus preços. Isso significa que outros aspectos influenciam na oscilação de valores no 


\section{- Cadernos de Ciénclas SOCIAIS APLICADAS}

mercado. Nesse sentido, tornou-se importante explorar algumas estatísticas descritivas referentes a outros atributos dos veículos. A tabela 4 sintetiza tais informações.

Tabela 4 - Estatísticas descritivas das variáveis nominais dos automóveis.

\begin{tabular}{lc}
\hline Características (variáveis) & Quantidade (\%) \\
\hline Possui 4 portas & 84,40 \\
Dispositivo de ar-condicionado & 62,30 \\
Dispositivo de alarme & 51,10 \\
Direção Elétrica/Hidráulica & 89,90 \\
Dispositivo de segurança (airbag) & 41,80 \\
Combustível flex & 90,20 \\
Motor superior a 1.000 cilindradas & 40,20 \\
Vidros elétricos & 75,10 \\
Cor preta & 24,60 \\
Cor branca & 15,80 \\
Cor prata & 36,60 \\
Cor vermelha & 9,80 \\
Cor dourada & 0,50 \\
Cor azul & 2,20 \\
Cor Cinza & 7,90 \\
\hline
\end{tabular}

Fonte: Dados da pesquisa (2018).

Observando os resultados da tabela 4 constata-se que a maioria dos automóveis pesquisados possuem quatro portas, ar-condicionado, dispositivo de alarme, direção elétrica ou hidráulica e vidros elétricos. Analogamente, verifica-se que menos da metade dos veículos possuem airbag e motor superior a 1.000 cilindradas. Com relação às cores, os dados revelaram que $77 \%$ da frota de usados e seminovos são compostos por automóveis nas cores preta, branca ou prata, conforme a Fenabrave (2017) destacou em seu anuário estatístico.

\section{Ajuste do modelo}

Com o intuito de ajustar um modelo de regressão linear múltipla capaz de produzir estimativas de alta confiabilidade para os preços dos carros usados e seminovos, as observações consideradas

Página 59 Caderno de Ciências Sociais Aplicadas, Vitória da Conquista/BA, vol. 15, nº 26, ano 15, p. 47-68, jul/dez 2018. 
atípicas (outliers) foram retiradas do modelo proposto após a fase exploratória de dados ${ }^{8}$. Assim, foram consideradas 326 observações válidas.

A técnica de ajustamento escolhida para o modelo foi a forward. Esse método consiste em iniciar o ajustamento do modelo sem incluir nenhuma variável explicativa, isto é, o modelo inicial é composto apenas pelo intercepto. Adicionalmente, a primeira variável a entrar no modelo será aquela que apresentar a maior correlação (em valores absolutos) com a variável dependente. Essa variável é adicionada ao modelo se pelo menos sua correlação além de ser a mais alta for estatisticamente significativa e incrementar positivamente o coeficiente de determinação $\left(\mathrm{R}^{2}\right)$. A próxima variável a ser acrescentada ao modelo seguirá a mesma lógica, depois de os efeitos da variável anterior serem ajustados para a variável dependente. Esse procedimento continua até que não existam mais variáveis explicativas com correlação significativa com a variável a ser explicada pelo modelo. Segundo Marocco (2007) e Hair et al. (2009), esse tipo de ajustamento é muito utilizado quando existem muitas variáveis independentes e, para evitar a inclusão de variáveis desnecessárias ao modelo, pode-se optar por não incluir uma variável adicional no modelo quando esta não provocar aumentos no $\mathrm{R}^{2}$. A tabela 5 apresenta a análise de variância para o modelo ajustado por meio da técnica forward.

Tabela 5 - Análise de variância para o modelo estimado pela técnica forward.

\begin{tabular}{lccccc}
\hline & $\begin{array}{c}\text { Soma de } \\
\text { quadrado }\end{array}$ & $\begin{array}{c}\text { Grau de } \\
\text { liberdade }\end{array}$ & $\begin{array}{c}\text { Quadrado } \\
\text { médio }\end{array}$ & Estatística F & P-valor \\
\hline Regressão & $2,1490 \mathrm{e}+10$ & 23 & 0,0934 & 88,55 & 0,000 \\
Resíduo & $2,6971 \mathrm{e}+9$ & 303 & 0,0089 & & \\
Total & $2,4188 \mathrm{e}+10$ & 326 & & & \\
\hline
\end{tabular}

Fonte: Dados da pesquisa (2018).

Com base nos resultados encontrados na tabela 5, identificou-se que o modelo ajustado aos dados é significativo ao nível de 1\% e 5\%, isto é, pelo menos uma das variáveis independentes possui efeito significativo sobre as oscilações da variável a ser explicada. Além disso, é importante destacar que o coeficiente de determinação ajustado encontrado para o modelo foi 0,855 . Isso significa que $85,5 \%$ da variabilidade observada nos preços de vendas dos carros usados e seminovos são explicados pelas variáveis que foram incluídas no modelo.

\footnotetext{
${ }^{8}$ Um valor é considerado outlier quando este apresenta valores muito distantes daqueles observados nas demais observações. Existem vários métodos para detecção de outliers, entre eles, o escore Z é muito usual. Para detalhes sobre o procedimento de eliminação de valores atípicos sugere-se Marocco (2007) e Hair et al. (2009).
}

Página 60 Caderno de Ciências Sociais Aplicadas, Vitória da Conquista/BA, vol. 15, nº 26, ano 15, p. 47-68, jul/dez 2018. 
Entretanto, a análise de variância contribui apenas para demonstrar que o modelo possui significância global. Para descobrir o efeito de cada variável independente sobre a dependente é necessário que se conheçam o sinal e os valores dos parâmetros "betas" estimados. Assim, foi realizada uma análise de tais coeficientes com o intuito de observar quais foram significativos e seu impacto sobre o preço dos carros. Os resultados são apresentados na tabela 6.

Tabela 6 - Resultados dos coeficientes encontrados pelo modelo de regressão.

\begin{tabular}{|c|c|c|c|c|c|}
\hline Variável & Coeficiente & $\begin{array}{l}\text { Erro padrão } \\
\text { robusto de } \\
\text { White }\end{array}$ & Estatística $t$ & P-valor & VIF \\
\hline $\bmod 5$ & $-4635,457$ & 971,415 & $-4,77$ & 0,000 & 1,95 \\
\hline $\mathrm{mt}$ & 3869,264 & 504,689 & 7,67 & 0,000 & 1,78 \\
\hline tc & $-3787,799$ & 1131,003 & $-3,35$ & 0,001 & 1,68 \\
\hline $\bmod 6$ & $-3432,056$ & 799,702 & $-4,29$ & 0,000 & 2,43 \\
\hline $\bmod 1$ & $-3186,909$ & 684,944 & $-4,65$ & 0,000 & 3,03 \\
\hline por & 2971,778 & 540,758 & 5,50 & 0,000 & 1,41 \\
\hline $\bmod 3$ & 2962,472 & 848,762 & $-3,49$ & 0,001 & 2,64 \\
\hline c2 & 2505,223 & 1098,764 & 2,28 & 0,023 & 4,81 \\
\hline $\bmod 2$ & 2464,895 & 730,5401 & $-3,37$ & 0,001 & 2,64 \\
\hline ar & 2241,344 & 444,345 & 5,04 & 0,000 & 1,54 \\
\hline id & $-1483,988$ & 106,905 & $-13,88$ & 0,000 & 3,70 \\
\hline$a b$ & 1192,870 & 598,200 & 1,99 & 0,047 & 2,04 \\
\hline al & 1062,929 & 444,429 & 2,39 & 0,017 & 1,23 \\
\hline $\mathrm{km}$ & $-0,165$ & 0,079 & $-2,08$ & 0,039 & 2,23 \\
\hline vid & $-205,233$ & 532,641 & $-0,39$ & 0,700 & 1,54 \\
\hline c4 & 2145,854 & 1246,180 & 1,72 & 0,086 & 4,58 \\
\hline c5 & 1822,522 & 1228,037 & 1,48 & 0,139 & 4,01 \\
\hline c3 & 1594,039 & 1009,326 & 1,58 & 0,115 & 5,79 \\
\hline $\mathrm{c} 1$ & 1115,735 & 1030,662 & 1,08 & 0,280 & 4,99 \\
\hline c6 & 1066,343 & 1637,514 & 0,65 & 0,515 & 1,85 \\
\hline $\bmod 4$ & $-484,403$ & 996,719 & $-0,49$ & 0,627 & 1,95 \\
\hline dir & 383,039 & 970,757 & 0,39 & 0,693 & 1,46 \\
\hline Constante & 33317,19 & 2179,992 & 15,28 & 0,000 & \\
\hline
\end{tabular}

Fonte: Dados da pesquisa (2018).

Com base nos resultados da tabela 6 , foi possível observar que das 22 variáveis propostas, 14 inicialmente se mostraram significativas aos níveis de 5\% e 1\%. Além disso, nota-se que a última variável a ser incluída no modelo com significância estatística foi a quilometragem $(\mathrm{km})$ dos veículos.

Quando existem muitas variáveis em um modelo de regressão linear múltipla uma das principais preocupações refere-se à existência de multicolinearidade entre as variáveis explicativas do modelo. Tal correlação prejudica o poder de explicação do modelo, pois verificada a sua presença, significa que uma

Página 61 Caderno de Ciências Sociais Aplicadas, Vitória da Conquista/BA, vol. 15, n 26, ano 15, p. 47-68, jul/dez 2018. 
ou mais variáveis estão explicando o mesmo elemento dentro do modelo, inflando a variância desse aspecto. Desse modo, a coluna VIF (Variance Inflator Factor) na tabela 6 busca identificar a presença de multicolinearidade no modelo em questão. A literatura especializada (MAROCCO, 2007; HAIR et al., 2009) recomenda que os valores observados no VIF devem ser inferiores a 5 para garantir a ausência de multicolinearidade. Observando os valores VIF das variáveis que foram estatisticamente significativas, ficou constatada a não existência de tal característica para o modelo ajustado.

Além disso, é importante destacar que na fase inicial da escolha do melhor modelo aplicado, foi constatada a presença de heterocedasticidade nos dados e, sendo assim, optou-se por utilizar o erro padrão robusto de White, pois este fornece valores (assintoticamente) mais robustos para os coeficientes estimados na presença de heterocedasticidade (WOOLDRIGDE, 2010). Inicialmente, a alternativa utilizada foi a transformação logarítmica nas variáveis métricas do estudo. Apesar de bastante usual na literatura especializada, essa transformação gerou uma perda de interpretação dos coeficientes estimados e, visando manter a simplicidade do modelo, manteve-se a variável em seus formatos originais, haja vista seus coeficientes estimados serem mais robustos.

Diante disso, ao analisar os coeficientes da regressão encontrados na tabela 6 foi possível perceber que a variável com maior impacto no preço dos automóveis foi a mod5. Uma interpretação para essa variável é que caso o carro em questão seja do modelo Corsa (mod5), em média, seu preço de venda é afetado negativamente em $\mathrm{R} \$ 4.635,45$. Ainda analisando o efeito dos modelos no preço médio de venda dos veículos populares, constata-se que mod3 (Novo Uno) e mod2 (Palio) afetam positivamente, em média, $\mathrm{R} \$ 2.962,47$ e $\mathrm{R} \$ 2.464,89$, respectivamente, o preço final de venda. Por outro lado, mod6 (Celta) e mod1 (Gol) possuem uma relação negativa com o preço. Se o automóvel pertencer ao modelo Celta, em média, seu preço é reduzido em $\mathrm{R} \$ 3.432,05$, ao passo que se o carro for do modelo Gol essa redução é de R \$3.186,90. Em relação ao modelo Fiesta ( $\bmod 4)$, seu coeficiente estimado não foi significativo, ou seja, não foi possível observar nesse modelo qual seria o efeito dessa característica no preço de venda dos carros populares.

Um fator externo ao modelo e que poderia ter influenciado os coeficientes para os veículos Corsa (mod5), Celta (mod6) e Gol (mod1) é a política governamental de fomento ao crédito e subsídios ao setor automobilístico, adotada principalmente entre os anos 2002 e 2012. Durante esse período, o Banco Central aumentou o volume de crédito para esse setor e o governo reduziu o Imposto sobre Produtos Industrializados (IPI). Com essas medidas a demanda por automóveis novos cresceu moderadamente, sobretudo em relação aos novos modelos de veículos com maiores opções de

Página 62 Caderno de Ciências Sociais Aplicadas, Vitória da Conquista/BA, vol. 15, n 26, ano 15, p. 47-68, jul/dez 2018. 
acessórios e, por esse motivo, julgados subjetivamente pelos consumidores como mais confortáveis, seguros, entre outros atributos. Assim, é possível que os modelos de carros supracitados sejam mais básicos, se comparados aos outros modelos investigados na pesquisa.

Em relação às cores dos automóveis, somente a cor branca (c2) apresentou coeficiente estatisticamente significativo ao nível de 5\%. Dessa forma, uma análise do impacto no preço das demais cores torna-se inapropriada. O mesmo fato pode ser constatado nas variáveis vid (vidros elétricos) e dir (tipo de direção). Observando os resultados encontrados na tabela 6, pode-se notar que, caso o automóvel possua a característica de ser branco, em média, seu preço de venda aumenta em R \$ $2.505,22$.

Seguindo a análise dos coeficientes da regressão, observou-se que a potência do motor é a segunda variável com maior poder de influenciar o preço médio de vendas dos veículos pesquisados. Se o carro possuir mais de 1.000 cilindradas, em média, seu preço é afetado positivamente em R \$3.869,26. Outras variáveis como por (4 portas), ar (ar-condicionado) e ab (air bag) também foram consideradas fontes de incremento no preço dos veículos, haja vista que os coeficientes encontrados foram positivos.

Finalizando a análise dos coeficientes, as variáveis id (idade do veículo) e $\mathrm{km}$ (quilometragem) impactaram negativamente a variável dependente de análise (preço de venda). Com base nos dados da tabela 6 constatou-se que, para cada ano adicional em idade, os automóveis populares têm, em média, seus preços de venda reduzidos em $\mathrm{R} \$ 1.483,98$. De forma semelhante, a quilometragem também influenciou negativamente os preços de venda. Para 1.000 quilômetros rodados adicionais os preços reduzem-se, em média, $\mathrm{R} \$ 165,00$.

\section{Análise de resíduo}

A análise dos resíduos do modelo é extremamente relevante, é nesse momento que se verifica se a equação estimada não violou os pressupostos de normalidade, homocedasticidade da variância e também a independência dos resíduos. A tabela 7 apresenta os resultados para a normalidade dos resíduos (teste Shapiro-Wilk), autocorrelação de $1^{\mathrm{a}}$ ordem dos erros (teste Durbin-Watson) e homocedasticidade da variância (teste White). 
Tabela 7 - Análise dos resíduos do modelo de regressão proposto.

\begin{tabular}{|c|c|c|c|c|}
\hline \multicolumn{2}{|c|}{ Teste Shapiro-Wilk } & \multirow{2}{*}{$\begin{array}{l}\text { Teste Durbin- } \\
\text { Watson } \\
\text { Estatística } d w\end{array}$} & \multicolumn{2}{|c|}{ Teste White } \\
\hline Estatística W & P-valor & & Estatística $\chi^{2}$ & P-valor \\
\hline 0,835 & 0,205 & 1,961 & 220,628 & 0,192 \\
\hline
\end{tabular}

Com relação à normalidade dos erros, os resultados da tabela 7 indicaram que os resíduos do modelo possuem distribuição normal. Tal fato fica evidenciado pelo teste de Shapiro-Wilk. Nesse teste, a hipótese nula deve ser aceita uma vez que esta propõe que os dados da amostra são provenientes de uma população com distribuição normal. Para a autocorrelação de $1^{a}$ ordem dos erros, foi utilizada a estatística Durbin-Watson e para tomar uma decisão sobre a conclusão do teste adota-se uma regra prática. Segundo Hair et al. (2009), para valores próximos a 2, a estatística dw conclui que não há autocorrelação dos erros e diz-se que não há associação linear de $1^{\mathrm{a}}$ ordem com os resíduos da regressão; para valores próximos de 0 tem-se uma correlação positiva, ao passo que valores próximos a 4 evidenciam uma correlação negativa. Conforme verificado na tabela 7 , a estatística $d w$ se aproxima satisfatoriamente de 2 , indicando a inexistência de autocorrelação.

Para que a análise dos resíduos fique completa, é necessário verificar o comportamento da variância dos erros. Tal procedimento é essencial para a precisão dos estimadores do modelo. Quando a variância dos resíduos possui algum comportamento sistemático, os parâmetros estimados pelo modelo se tornam ineficientes e deixam de ter a menor variância possível. Esse problema se denomina heterocedasticidade. Conforme comentado anteriormente, foi detectada a presença de heterocedasticidade no modelo inicial no momento de verificação dos pressupostos da regressão. Portanto, foi necessário utilizar erros padrão robustos à heterocedasticidade e, assim, um novo modelo foi gerado com estimadores robustos. Após executar o modelo final pela técnica forward, foi aplicado o teste de White e, de acordo com os resultados obtidos na tabela 7, é possível afirmar que o problema foi resolvido e que a hipótese nula do referido teste foi aceita, ou seja, a variância dos erros não possui nenhum comportamento sistemático, confirmando a hipótese de homocedasticidade.

Assim, perante o que foi exposto, tanto no que diz respeito ao grau de ajustamento do modelo quanto na análise dos erros, é possível afirmar que o modelo é adequado para realizar previsões nos preços de carros usados e seminovos populares vendidos no mercado doméstico brasileiro. Logo, pode-se enunciar, mediante a equação 4, o modelo final que apresenta as variáveis com estimadores estatisticamente significativos:

Página 64 Caderno de Ciências Sociais Aplicadas, Vitória da Conquista/BA, vol. 15, nº 26, ano 15, p. 47-68, jul/dez 2018. 
$P=33317,19-4635,45 \bmod 5+3869,26 m t-3787,79 t c-3432,05 \bmod 6$

$-3186,90 \bmod 1+2971,77$ por $+2962,47 \bmod 3+2505,22 c 2+2464,89 \bmod 2$

$+2241,34 a r-1483,98 i d+1192,87 a b+1062,92 a l-0,165 k m$

\section{Considerações finais}

O presente estudo buscou determinar um modelo de regressão linear múltipla para estimar os preços dos automóveis usados e seminovos no mercado doméstico brasileiro. Os resultados demonstraram que $85,5 \%$ da variabilidade nos preços dos veículos são explicados por 14 variáveis: quilometragem $(\mathrm{km})$, idade (id), potência $(\mathrm{mt})$ do motor (1.000 cilindradas ou maior), combustível único ou flex (tc), existência de ar-condicionado (ar), veículo com 2 ou 4 portas (por), existência de dispositivo de alarme (al), modelos dos automóveis (Gol, mod1; Palio, mod2; Novo Uno, mod3, Corsa, mod5; Celta, mod6), cor branca (c2), existência de airbag (ab) e presença de dispositivo elétrico nos vidros (vid).

Além disso, o modelo estimado pela equação 4 foi julgado adequado tendo em vista que atendeu aos pressupostos de normalidade na distribuição dos resíduos, homocedasticidade da variância dos erros, ausência de autocorrelação serial dos erros e inexistência de multicolinearidade.

Com relação às características qualitativas dos automóveis, verificou-se que a potência do motor foi o atributo que mais contribuiu para elevar o preço médio de venda dos veículos pesquisados. Ainda com relação às variáveis dummies, é importante destacar o impacto da variável cor branca. Essa cor foi a única a apresentar coeficiente significativo em relação às demais. Assim, pode-se afirmar que um veículo tende a sofrer aumento de preço caso possua essa característica.

Perante o que foi apresentado no presente trabalho, pode-se concluir que o modelo encontrado contribui para a redução da assimetria informacional, pois esclarece tanto para compradores quanto para vendedores quais características, de fato, impactam de maneira significativa o preço de venda dos carros usados e seminovos.

Apesar de atingir o objetivo proposto, é importante salientar que o modelo encontrado possui limitações como, por exemplo, o fato de não levar em consideração a cidade de cada uma das observações. Outra limitação do estudo está ligada à qualidade dos veículos pesquisados. Uma vez que essa variável é de difícil mensuração, trabalhos posteriores poderiam determinar um conjunto de variáveis que funcionassem como uma proxy para esse atributo do veículo. Assim, para estudos futuros,

Página 65 Caderno de Ciências Sociais Aplicadas, Vitória da Conquista/BA, vol. 15, n² 26, ano 15, p. 47-68, jul/dez 2018. 
seria interessante que outro modelo fosse ajustado de tal maneira que essas variáveis estivessem incluídas. Além disso, seria importante que outras variáveis como número de revisões realizadas em concessionárias e preço de multas atreladas ao registro nacional de veículos do carro, fossem testadas para tornar o modelo proposto mais realístico e com maior poder de explicação.

\section{Referências}

AKERLOF, G. A. The Market of "Lemons": Quality uncertainty and market mechanism. The Quarterly Journal of Economics, v. 84, n. 3, 488-500, 1970.

ALBANEZ, T.; VALLE, M. R. Impactos da assimetria de informação na estrutura de capital de empresas brasileiras abertas. Revista Contabilidade \& Finanças USP, v. 20, n. 51, p. 6-27, 2009.

ASSOCIAÇÃO NACIONAL DOS FABRICANTES DE VEÍCULOS AUTOMOTORES. Novembro registra melhor mês da história em exportações. Disponível em: $<$ http://www.anfavea.com.br/docs/06.12.17_PressRelease_Resultados_Novembro.pdf> Acesso em: 08/04/2018.

BAUMGARTEN JR, A. L. Demanda de automóveis no Brasil. Revista Brasileira de Economia, v. 26, n. 2, p. 203-297. 1972.

BELO, N. M.; BRASIL, H. G. Assimetria informacional e eficiência semiforte do mercado. RAE, v. 46, n. 1, 2006.

CASOTTI, B. P.; GOLDENSTEIN, M. Panorama do setor automotivo: as mudanças estruturais da indústria e as perspectivas para o Brasil. BNDES Setorial, v. 28, p. 147-188, 2008a.

Setorial, n. 7, 2008b.

O novo ciclo de investimentos do setor automotivo brasileiro. BNDES Informe

DANTAS, R. A.; MAGALHÃES, A. M.; VERGOLINO, J. R. O. Avaliação de imóveis: a importância dos vizinhos no caso de Recife-PE. Economia Aplicada, v. 11, n. 2, p. 231-251, 2007.

DE NEGRI, J. A. Elasticidade renda e elasticidade preço da demanda de automóveis. IPEA: Texto para discussão 558. 1998.

FAUTH, K. M.; MORAIS, I. A. C.; CLEZAR, R. V. O mercado de automóveis, ônibus e caminhões no Brasil 1996-2008. IN: XXXVII ENANPEC, Foz do Iguaçu, 2009.

FEDERAÇÃO NACIONAL DA DISTRIBUIÇÃO DE VEÍCULOS. Vendas de usados também crescem em 2017. Disponível em:

Página 66 Caderno de Ciências Sociais Aplicadas, Vitória da Conquista/BA, vol. 15, nº 26, ano 15, p. 47-68, jul/dez 2018. 
$<$ http://www3.fenabrave.org.br:8082/plus/modulos/noticias/ler.php?cdnoticia=10977\&cdcategoria= 1\&layout $=$ noticias $>$. Acesso em 09/04/2018.

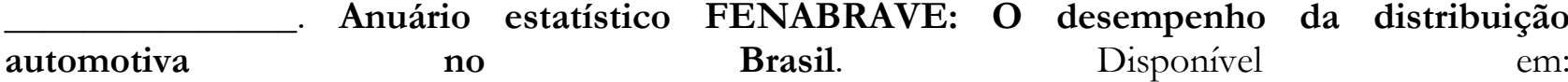
$<$ http://www3.fenabrave.org.br:8082/plus/modulos/listas/index.php?tac=indices-enumeros\&idtipo $=6 \&$ layout $=$ indices-e-numeros $>$. Acesso em: 11/04/2018.

FONSECA, R. Quality change in brazilian automobiles. IPEA: Texto para discussão 462. 1997.

FRANÇA, J. M. F. Um modelo para avaliar o impacto da assimetria de informação na gestão de organizações sociais com aplicação às universidades federais brasileiras. 2005, 96p. Tese de Doutorado (Doutorado em Engenharia de Produção). Santa Catarina, UFSC, 2005.

GAVAZZA, A.; LIZZERI, A.; ROKETSKIY, N. A quantitative analysis of the used-car market. American Economic Review, v. 104, n. 11, p. 3668-3700, 2014.

GODOY, M. R.; SILVA, E. N.; NETO, G. B. Planos de saúde e a teoria da informação assimétrica. Porto Alegre, UFRGS, 2004.

HAIR, J. F.; BLACK, W. C.; BABIN, B. J. ANDERSON, R. E.; TATHAM, R. L. Análise Multivariada de Dados. 6 edição, Porto Alegre: Bookman, 2009.

MARCONDES, R. L. Padrão-Ouro e estabilidade. Estudos Econômicos, v. 28, n. 3, p. 533-559, 1998.

MAROCCO, J. Análise estatística com utilização do SPSS. 3ª edição, Lisboa: Silabo, 2007.

MATTOS, L. B.; BARROS, A. M. Análise da estrutura do mercado brasileiro de carros populares. Revista de Economia e Agronegócio, v. 4, n. 3, p. 365-386, 2006.

OLIVEIRA, R. Diferença aumenta entre preços sugeridos e os referenciais da tabela FIPE. Disponível em: <https://www.noticiasautomotivas.com.br/diferenca-aumenta-entre-precos-sugeridose-os-referenciais-da-tabela-fipe/>. Acesso em: 08/04/2018.

PINDYCK, R. S.; RUBINFELD, D. L. Microeconomia. 6ª edição, São Paulo: Pearson, 2006.

RESENDE, C. B.; SCARPEL, R. A. Importância das características na precificação dos veículos nacionais. Produção, v. 19, n. 2, p.345-358. 2009. 


\section{Cadernos de Ciéncias SOCIAIS APLICADAS}

SANTOS, A. M. H. Testando da validade da Lei do Preço Único: Análise do mercado de carros usados no Brasil. 2016, 46p. Trabalho de Conclusão de Curso (Curso de Ciências Econômicas). Brasília, Distrito Federal, UnB, 2016.

SILVEIRA, L.; LEE BURNQUIST, H.; RODRIGUES, F.; PESSINI, M. M. Análise econométrica da demanda brasileira por veículos a álcool. IN: XLIV Congresso da Sociedade Brasileira de Economia e Sociologia Rural. Anais Ceará, 2006.

SOUZA, A.; AVILA, S. C.; SILVA, W. V. Modelos de preços hedônicos para estimar a relação preçosatisfação na compra de veículos populares novos. Revista Economia \& Gestão, v. 7, n. 15, p. 31-45, 2007.

TAVARES, F. A. O.; MOREIRA, A. C.; PEREIRA, E. T. Assimetria de informação no mercado imobiliário em Portugal. Revista de Administração da UNIMEP, v. 11, n. 3, p. 196-220, 2013.

VARIAN, H. Microeconomia: Princípios Básicos. $7^{\text {a }}$ edição, Rio de Janeiro: Elsevier, 2006.

WOOLDRIGDE, J. M. Introducción a la econometría: un enfoque moderno. $4^{a}$ edición, México: CENGAGE Learning, 2010.

ZONATTO, V. C. S.; LAVARDA, C. E. F. Evidências dos efeitos da participação orçamentária na assimetria de informação, estresse, ocupacional e desempenho no trabalho. IN: XIX Congresso Brasileiro de Custos. Anais Florianópolis, 2017. 